\title{
Characterization of natural radioactivity in the BSUIN and EUL underground laboratories based on the developed standard scheme
}

\author{
Katarzyna Szkliniarz ${ }^{a} *$, Agata Walencik-Łata ${ }^{a}$, Jan Kisiel ${ }^{a}$, Kinga Polaczek-Grelik ${ }^{b}$, \\ Karol Jędrzejczak ${ }^{c}$, Marcin Kasztelan ${ }^{c}$ and Jacek Szabelski ${ }^{c}$ \\ aUniversity of Silesia in Katowice, August Chelkowski Institute of Physics, \\ 75 Putku Piechoty 1, Chorzów, Poland \\ bNU-Med Cancer Diagnosis and Treatment Centre Katowice, \\ Ceglana 35, Katowice, Poland \\ cNational Centre for Nuclear Research, \\ 28 Pułku Strzelców Kaniowskich 69, Łódź, Poland \\ E-mail: katarzyna.szkliniarz@us.edu.pl, agata.walencik@us.edu.pl, \\ jan.kisiel@us.edu.pl, kinga.grelik@gmail.com, \\ karol.jedrzejczak@ncbj.gov.pl, marcin.kasztelan@ncbj.gov.pl, \\ jacek.szabelski@ncbj.gov.pl
}

\begin{abstract}
One of the most critical parameters describing underground laboratories is their natural radioactivity. Natural radioactivity depends on several factors, such as the depth at which the UL is located, local geology, and the materials used to reinforce the underground spaces. For this purpose, a standard scheme has been prepared, utilizing which one can quickly characterize and compare underground locations regarding their natural radiation. This article presents a scheme for Callio Lab, which includes in-situ measurements and laboratory analysis of rock and water samples.
\end{abstract}

\section{"Presenter}




\section{Introduction}

Underground laboratories (ULs) are mainly used for modern physics experiments searching for rare phenomena like proton decays or dark matter particles. However, more and more often, they find other uses. That is why the BSUIN (Baltic Sea Underground Innovation Network) project was created in 2017 [1]. The project aimed to develop the capabilities of underground laboratories operating in the Baltic Sea region and establish a network of underground laboratories. The project was completed in 2020 and is still being continued in the EUL (Empowering Underground Laboratories Network Usage) project [2].

One of the most critical parameters describing underground locations is their natural background radiation (NBR) characteristics, and it is also one of the tasks of both projects. Natural radioactivity in underground laboratories comes mainly from the cosmic ray muon flux, the decay of radionuclides from decay chains of uranium and thorium $\left({ }^{238} \mathrm{U},{ }^{232} \mathrm{Th}\right)$, and long-lived radionuclides $\left({ }^{40} \mathrm{~K}\right)$, the spontaneous fission of $\mathrm{U}$ and $\mathrm{Th}$, and the interaction of neutrons from $(\alpha, \mathrm{n})$ reactions. The level of natural radiation depends on few parameters. The muon flux decreases with the increase of the depth of the underground rooms. Another factor is local geology, i.e., the presence of naturally occurring radionuclides of a given site and the elemental composition. Therefore, the natural radioactivity of different rock layers/deposits may differ significantly from each other. The next issue is the materials used for the construction and strengthening of underground rooms. Materials such as cement or concrete can reduce the natural radioactivity of the rock. On the other hand, these materials may contain an increased concentration of radionuclides. All these parameters have a significant impact on the level of natural background radiation, so a standard scheme for the description of separate laboratories in the BSUIN project was developed. It allows easily, quickly, and transparently to compare the underground rooms of one of the UL and compare several underground laboratories. It is beneficial for users of underground laboratories who conduct their research and projects there because the key parameter is selecting the right place.

The presented article describes the standard scheme developed on one of the underground laboratories of the BSIUIN project, Callio Lab, located in Finland.

\section{Standard scheme for Callio Lab}

The scheme prepared for Callio Lab consists of three parts containing information on measurement locations, in-situ measurements, and laboratory analyses of water and rock samples.

The scheme includes, among others, a schematic plan of the hall with a marked place in-situ measurements, a description of the site, and photos during the measurements. Also, measurement conditions, measurement equipment used, and measure results take into account. Additionally, in part of laboratory analysis of water and rock samples, descriptions of chemical procedures performed before measurements are shown.

\subsection{General information}

The Callio Lab underground laboratory is located in the Pyhäsalmi mine in the central part of Finland. It is the oldest and most profound mine in Europe. Callio Lab has seven laboratories situated at depths from $75 \mathrm{~m}$ to $1440 \mathrm{~m}$, which have various applications. Physics research (Lab 
2 and Lab 5), the EMMA experiment - Experiment with a MultiMuon Array (Lab 1), plant breeding (Lab 4), and underground information modeling (Lab 3) are carried out in the underground rooms [3]. Coordinates to the facility are $63^{\circ} 39^{\prime} 31^{\prime \prime}$ North and $26^{\circ} 02^{\prime} 28^{\prime \prime}$ East at the altitude of $143 \mathrm{~m}$. The underground laboratory also has its website: www.calliolab.com. The scheme also includes a map with a marked location (Fig. 1a), information about the place where the data is stored, and the names of the responsible scientists for performed measurements.

(a)

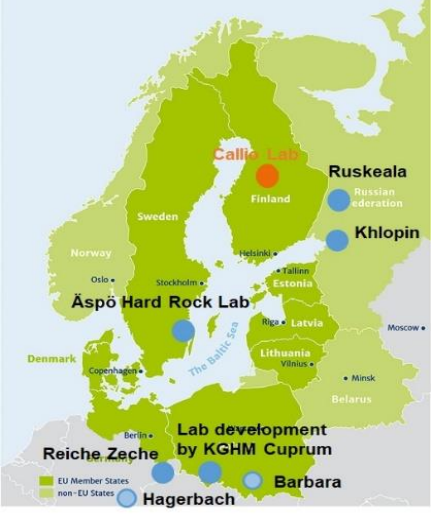

(b)

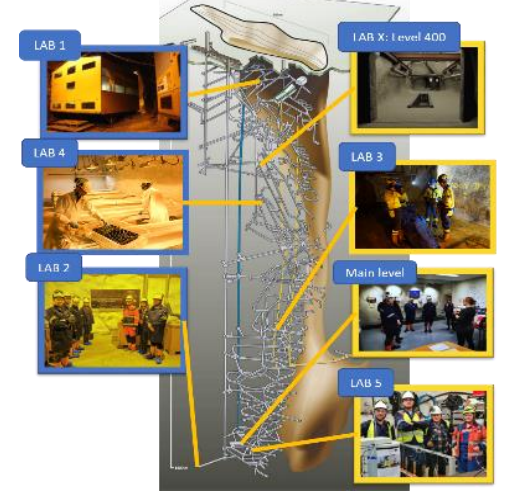

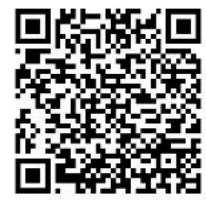

Callio Lab

Fig.1. (a) Map of the Baltic Sea Region with labeled underground laboratories participating in the BSUIN and EUL projects, (b) Pyhäsalmi mine layout with the locations of the laboratories.

\subsection{Measurements of the NBR in Underground Laboratory}

This chapter presents the results and description of the in-situ measurements carried out in Callio Lab. Fig. 1b shows the Pyhäsalmi mine layout with the locations of the laboratories.

Measurements were carried out in Lab 2 with dimensions of $9 \mathrm{~m} \times 15 \mathrm{~m} \times 8 \mathrm{~m}$ and located on the depth below the surface around $4000 \mathrm{~m}$ w.e. Air volume exchange rate in Lab 2 is $10 \mathrm{~m}^{3} / \mathrm{s}$. At the same time, an environmental condition such as average temperature and the average humidity is $29.9^{\circ} \mathrm{C}$ and $25.4 \%$, respectively.

\subsubsection{In-situ gamma-ray measurements}

The in-situ gamma-ray measurement was performed by using portable gamma-ray spectroscopy (GR4020, Canberra Ind., USA) and HPGe (high purity germanium) coaxial detector (with $40 \%$ of detection relative efficiency). The multichannel analyzer (InSpector ${ }^{\mathrm{TM}} 2000$ ) and special software packages (Genie ${ }^{\mathrm{TM}} 2000$ v.3.2.1) were used to register and analyse the spectra. Energy calibration was performed using seven-sealed radioactive sources. While, the efficiency calibration was carried out using the geometry of room/box with internal surface contamination, modeled in Geometry Composer software (ISOCS ${ }^{\mathrm{TM}}$ software). Gamma radiation spectra were recorded in the energy range 7-3150 keV.

Measurements were performed at seven different Lab2 (Hall 2 and Hall 1) sites, including measurement sites such as right and left corners, center, and measures near a hole in the wall, also with using collimators. For this work, the results of measurements for one measuring point (MP7left corner of Hall 2) in Lab 2 are presented to more accurately illustrate the obtained results. 
During measurements in MP7, the HPGe detector was installed horizontal (oriented parallel to the floor) $1 \mathrm{~m}$ above the floor. Measurement of the gamma-ray spectrum was done from free space without the use of collimators (Fig.2).

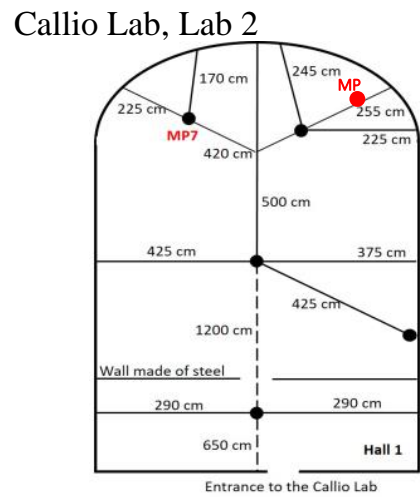

The photos during in-situ measurements:
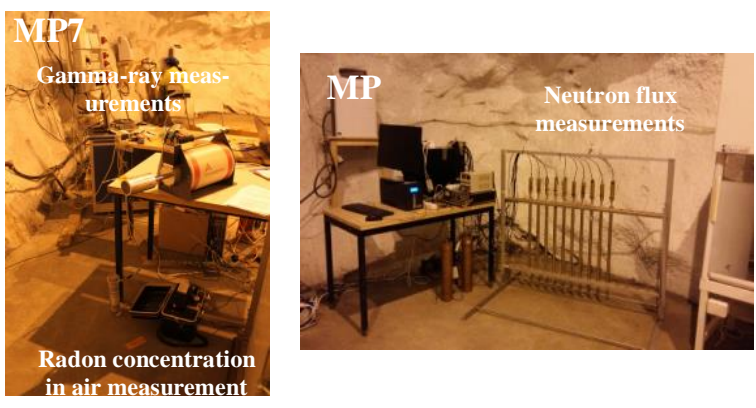

Fig. 2. Schematic plan of Lab 2 with marked MP7 and MP sites where the in-situ measurements were performed and the photos during measurements.

The spectrum gamma-ray registered in MP7 is presented in Fig. 3.

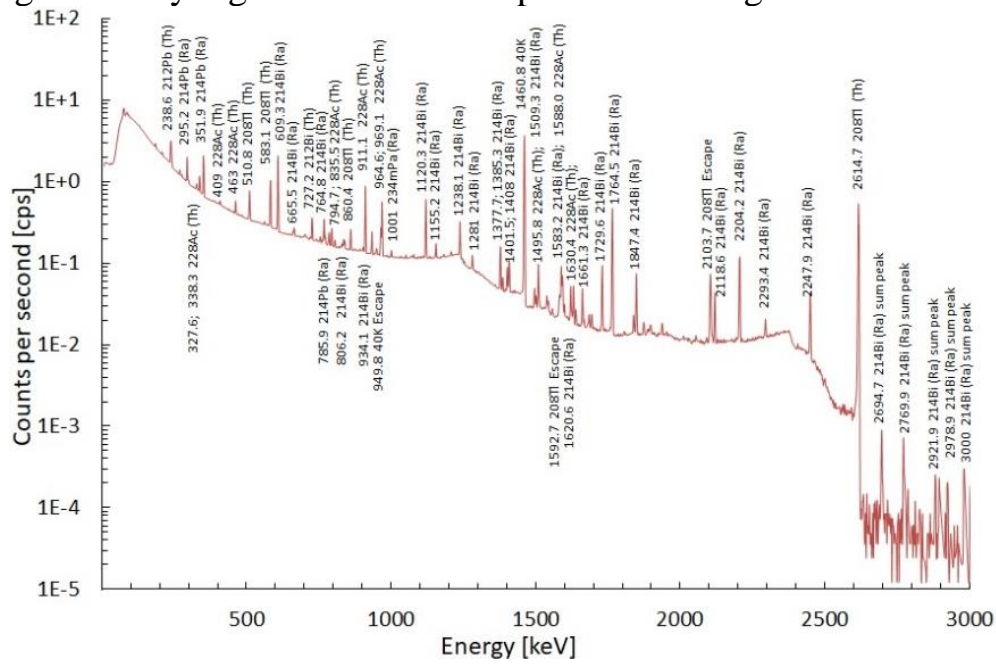

Fig. 3. In-situ gamma-ray spectrum registered in MP7 by the portable HPGe detector.

Based on the recorded spectrum, qualitative analysis of the spectrum was made and containing isotope identification and the energy of each registered gamma line, net area of the photopeak on the spectrum, and counts per second. The isotopes identified were: ${ }^{234} \mathrm{Th},{ }^{226} \mathrm{Ra}$, ${ }^{214} \mathrm{~Pb},{ }^{214} \mathrm{Bi},{ }^{234 \mathrm{~m}} \mathrm{~Pa}$ from uranium series, ${ }^{228} \mathrm{Ac},{ }^{212} \mathrm{~Pb},{ }^{208} \mathrm{Tl},{ }^{212} \mathrm{Bi}$ from thorium series, ${ }^{219} \mathrm{Rn}$ from actinium series, and ${ }^{40} \mathrm{~K},{ }^{239} \mathrm{U}$, and ${ }^{237} \mathrm{U}$. Total counts per second for tested energy range was $653 \pm 26$, gamma-ray flux was $75.5 \pm 7.6\left[\mathrm{~cm}^{-2} \mathrm{~s}^{-1}\right]$ and gamma-ray dose was $0.970 \pm 0.139[\mu \mathrm{Sv} / \mathrm{h}]$. While radioisotopes that have the main contributions in the effective dose are: ${ }^{40} \mathrm{~K}(96.42 \pm 13.64$ $\mathrm{pSv} / \mathrm{s}(35.78 \%)),{ }^{214} \mathrm{Bi}(77.17 \pm 11.10 \mathrm{pSv} / \mathrm{s}(28.64 \%))$ from uranium series, and ${ }^{208} \mathrm{Tl}(57.44 \pm 8.14$ $\mathrm{pSv} / \mathrm{s}(21.32 \%))$ and ${ }^{228} \mathrm{Ac}(26.01 \pm 3.81 \mathrm{pSv} / \mathrm{h}(9.65 \%))$ from thorium series. Another value determined based on the recorded gamma radiation spectrum was the apparent activity for each identified radioisotope. The highest activity was determined for ${ }^{40} \mathrm{~K}$, which is $191.55 \mathrm{~Bq} / \mathrm{cm}^{2}$, and for ${ }^{237} \mathrm{U}$ and ${ }^{239} \mathrm{U}$, which are $95.16 \mathrm{~Bq} / \mathrm{cm}^{2}$ and $52.79 \mathrm{~Bq} / \mathrm{cm}^{2}$, respectively. 


\subsubsection{Measurements of the radon concentration in air}

The measurement radon concentration in air was performed using the RAD7 electronic radon detector (Durridge) for $24 \mathrm{~h}$ (measurement cycle $1 \mathrm{~h}$ ). The detector was located on the floor, near the HPGe detector (Fig. 2). During the measurement, the room ventilation was turned on, the temperature was $30.1{ }^{\circ} \mathrm{C}$, the humidity was $9.0 \%$, and a drying unit was applied. The average value of radon concentration in the air at the MP7 point was $277.8 \pm 10 \% \mathrm{~Bq} / \mathrm{m}^{3}$. The monitoring of radon concentration in MP7 is shown in Fig. 4.

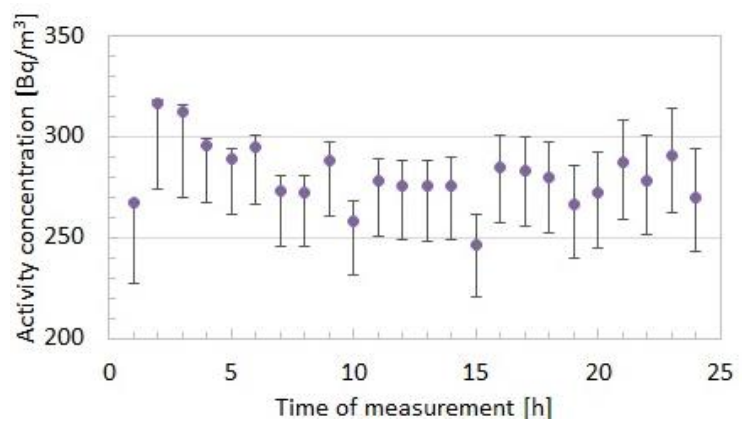

Fig. 4. Monitoring of radon concentration in MP7.

\subsubsection{Measurements of the neutron flux}

The standard method of gas-proportional counters filled with ${ }^{3} \mathrm{He}$ (helium counter) at $4 \mathrm{~atm}$ was used to measure the thermal neutron flux. Each counter (manufacturer by ZDAJ EM425A50) was $50 \mathrm{~cm}$ long, has $2.5 \mathrm{~cm}$ in diameter, had its independent electronics mounted in a brass tube, powered and controlled by the leading PC via USB cable. Measurement of neutron flux was performed in the MP site about $1 \mathrm{~m}$ away from the wall (Fig. 2). Ten bare helium proportional counters were set in a flat vertical tray located parallel to the wall of Hall 2. Signal amplitude spectra for each counter were collected, the neutron part of the spectrum was extracted, and the neutron counting rate was determined. The agreement between measurements in laboratory conditions and Monte Carlo calculations at the level of a few percent was achieved. The thermal neutron measurement was $45.5 \mathrm{~h}$, the average neutron counting rate was $14.78 \pm 0.6$, while the calculated neutron flux was $(1.73 \pm 0.10) \times 10^{-5} \mathrm{~cm}^{-2} \mathrm{~s}^{-1}[4]$.

\subsection{Laboratory analyses of the water samples}

Water samples were also taken from the investigated locations for detailed laboratory analysis in an external laboratory. The measurements included determining the concentration of radioisotopes of uranium $\left({ }^{234,238} \mathrm{U}\right)$ and radium $\left({ }^{226,228} \mathrm{Ra}\right)$.

The analysis was performed for 3 samples. The two water samples came from two pipes which collect the water seeping through the rocks behind Hall 2 of Lab 2 (PH-102 and PH-103), while the third sample was collected directly from the rock outside Lab 2 in its nearby (PH500907). Samples were taken directly into polyethylene bottles [4].

\subsubsection{Uranium concentration in water samples}

The concentration of uranium $\left({ }^{234 \mathrm{U}, 238} \mathrm{U}\right)$ radioisotopes in the water samples were determined by semiconductor alpha spectrometry using spectrometer 7401VR from Canberra (Packard) (Fig. 
5a). Before measurement, a radiochemical procedure was used to prepare the source for alpha spectrometry. Samples were acidified with $\mathrm{HNO}_{3}$ and spiked with a known amount of ${ }^{232} \mathrm{U}$. The separation of $U$ was performed using the anion exchange resin Dowex $1 \times 8\left(\mathrm{Cl}^{-}\right.$type, 200-400 mesh). The alpha spectrometry source was prepared by co-precipitation of $\mathrm{U}$ with $\mathrm{NdF}_{3}$ and subsequent deposition on polypropylene discs. The measurement time of the spectra was from 2 to 3 days. An exemplary alpha spectrum for a sample PH-500907 is shown in Fig. 5b. The detection limit for both uranium radioisotopes was $0.5 \mathrm{mBq} / \mathrm{L}$ and $0.5 \mathrm{~L}$ of destilled water initial sample volume.

(a)

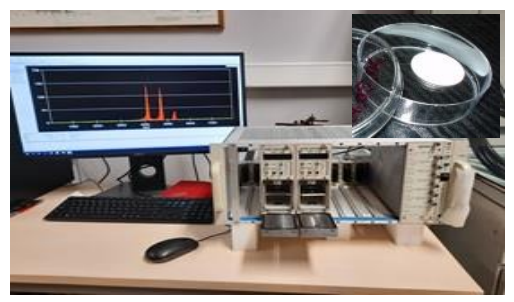

(b)

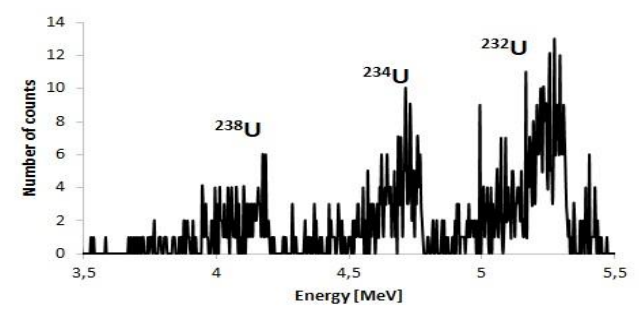

Fig. 5. (a) The spectrometer 7401VR (Canberra, USA) and alpha source, (b) spectrum alpha for PH500907 sample.

The uranium concentration of ${ }^{238} \mathrm{U}$ in the $\mathrm{PH}-102$ and $\mathrm{PH}-103$ samples were below the detection limit. However, for the PH-500907 sample, it was $6.5 \pm 0.7 \mathrm{mBq} / \mathrm{L}$. The activity concentration of ${ }^{234} \mathrm{U}$ was $4.9 \pm 0.7 \mathrm{mBq} / \mathrm{L}, 0.8 \pm 0.2 \mathrm{mBq} / \mathrm{L}$, and $11.1 \pm 0.9 \mathrm{mBq} / \mathrm{L}$ for the $\mathrm{PH}-102$, $\mathrm{PH}-103$, and PH-500907 samples, respectively [4].

\subsubsection{Radium concentration in water samples}

The radium concentration in the water samples was determined using an LSC technique and 1414 Win Spectral $\alpha / \beta$ liquid scintillation counter (LSC) from Wallac (Fig. 6a).

(a)

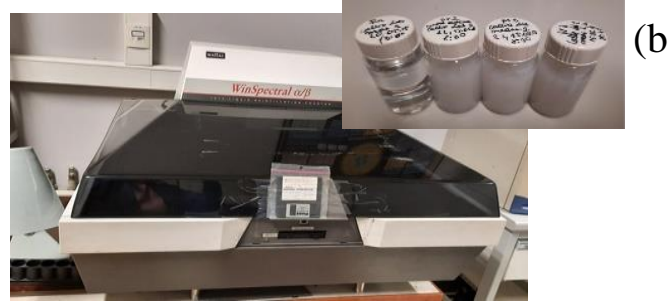

(b)

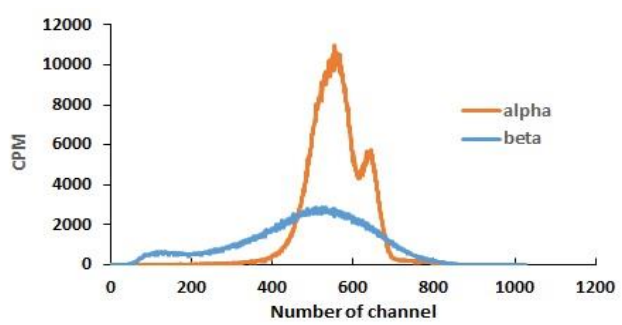

Fig. 6. (a) The $1414 \mathrm{Win}$ Spectral $\alpha / \beta$ liquid scintillation counter (from Wallac) and water samples in scintillation vials filled with a scintillation cocktail, (b) spectrum for PH-500907 sample.

Before measurements, a chemical procedure was performed. Measurements were made once a day (counting time 1 hour) for one month. The activity of ${ }^{226} \mathrm{Ra}$ was calculated from the $\alpha$ part of the spectrum, and ${ }^{228} \mathrm{Ra}$ activity was estimated from a high-energy $\beta$ spectrum from ${ }^{228} \mathrm{Ac}$ being in equilibrium with ${ }^{228} \mathrm{Ra}$. The detection limit was $10 \mathrm{mBq} / \mathrm{L}$ for ${ }^{226} \mathrm{Ra}$ and $30 \mathrm{mBq} / \mathrm{L}$ for ${ }^{228} \mathrm{Ra}(1$ $\mathrm{h}$ counting time and $2 \mathrm{~L}$ of water initial sample volume). Exemplary alpha and beta spectra for a sample PH-500907 are shown in Fig. 6 b. 
The activity concentration of the ${ }^{226} \mathrm{Ra}$ isotope in the tested samples was: $116.6 \pm 2.7 \mathrm{mBq} / \mathrm{L}$, 15.1 $\pm 0.4 \mathrm{mBq} / \mathrm{L}$, and $54.9 \pm 1.3 \mathrm{mBq} / \mathrm{L}$ for $\mathrm{PH}-102, \mathrm{PH}-103$, and $\mathrm{PH}-500907$, respectively. The activity concentration of the ${ }^{228} \mathrm{Ra}$ isotope was: $10.7 \pm 4.5 \mathrm{mBq} / \mathrm{L}, 6.1 \pm 0.9 \mathrm{mBq} / \mathrm{L}$, and $36.0 \pm 2.8$ $\mathrm{mBq} / \mathrm{L}$ for PH-102, PH-103, and PH-500907, respectively [4].

\subsection{Laboratory analyses of the rock samples}

Rock samples were taken from the investigated locations for detailed laboratory analysis in an external laboratory. The measurements included determining the concentration of radioisotopes of uranium $\left({ }^{234,238} \mathrm{U}\right)$ and radium $\left({ }^{226} \mathrm{Ra},{ }^{228} \mathrm{Ra}\left({ }^{232} \mathrm{Th}\right)\right)$ and potassium $\left({ }^{40} \mathrm{~K}\right)$.

Rock samples were collected from various parts Lab 2, which included, among others: wall shotcrete, bedrock taken from the corridor and entrance to Hall 2, concrete from the floor Hall 2.

\subsubsection{Uranium concentration in rock samples}

The measurements of ${ }^{234,238} \mathrm{U}$ concentrations in rock samples were performed using the same technique as the water samples - $\alpha$ spectrometry technique and 7401VR spectrometer from Canberra. Before measurements, the radiochemical procedure was done. In the first step, the wetmineralization of the rock sample was made with the use of hot acids: $\mathrm{HF}, \mathrm{HNO}_{3}, \mathrm{HCl}$ with $\mathrm{H}_{3} \mathrm{BO}_{3}$. The next steps were similar to those described in the 2.3.1 section. The rock samples were measured for an average of 2 to 3 days. The detection limit was $0.4 \mathrm{mBq}$ per sample for both ${ }^{234,238} \mathrm{U}$ isotopes.

The average concentration of uranium isotopes for shotcrete was $71.55 \pm 3.6 \mathrm{~Bq} / \mathrm{kg}$ and $72.25 \pm 3.7 \mathrm{~Bq} / \mathrm{kg}$ for ${ }^{234} \mathrm{U}$ and ${ }^{238} \mathrm{U}$, respectively. For concrete sample taken from the floor was $24.1 \pm 1.5 \mathrm{~Bq} / \mathrm{kg}$ and $25.8 \pm 1.6 \mathrm{~Bq} / \mathrm{kg}$ for ${ }^{234} \mathrm{U}$ and ${ }^{238} \mathrm{U}$, respectively. On the other hand, the concentration of uranium isotopes for four rock samples taken from the corridor was on average $7.1 \pm 0.8 \mathrm{~Bq} / \mathrm{kg}$ and $7.0 \pm 0.5 \mathrm{~Bq} / \mathrm{kg}$ for ${ }^{234} \mathrm{U}$ and ${ }^{238} \mathrm{U}$, respectively [4].

\subsubsection{Radium, thorium, and potassium concentration in rock samples}

Measurements concentration of radium, thorium, and potassium isotopes in the rock samples were performed by gamma spectroscopy using lead-shielded HPGe detectors with the detection relative efficiency of 25-37\%. The acquisition and analysis of the spectra were made using Genie $2000^{\mathrm{TM}}$ software. Energy calibration and activity concentration of the analyzed isotopes were obtained based on reference materials. Based on registered spectra, the activity of ${ }^{40} \mathrm{~K}$ was calculated from a single $1460 \mathrm{keV}$ line. The activity of ${ }^{226} \mathrm{Ra}$ was calculated as the weighted mean of the values obtained from the ${ }^{214} \mathrm{~Pb}(295.2,351.9 \mathrm{keV})$ and ${ }^{214} \mathrm{Bi}(609.3,1120.3 \mathrm{keV})$ isotopes, while ${ }^{228} \mathrm{Ra}$ activity from ${ }^{228} \mathrm{Ac}(338.3 \mathrm{keV}$ and $911.1 \mathrm{keV})$. The total duration of a single measurement depended on the sample activity and was about 1 to 3 days. Before the measurements, the samples were adequately prepared. All samples were dried, crushed, ground to a grain diameter of less than $1 \mathrm{~mm}$, mixed, and sealed in Marinelli containers. Then, after about one month (the time needed to achieve secular equilibrium in the thorium and uranium series), their measurements were made in lead-copper shielding. 
The average concentration of ${ }^{226} \mathrm{Ra},{ }^{228} \mathrm{Ra}\left({ }^{232} \mathrm{Th}\right)$, and ${ }^{40} \mathrm{~K}$ for shotcrete was $65.6 \pm 2.0 \mathrm{~Bq} / \mathrm{kg}$, $44.1 \pm 2.3 \mathrm{~Bq} / \mathrm{kg}, 899 \pm 50 \mathrm{~Bq} / \mathrm{kg}$, respectively. The concentration of ${ }^{226} \mathrm{Ra},{ }^{228} \mathrm{Ra}\left({ }^{232} \mathrm{Th}\right)$, and ${ }^{40} \mathrm{~K}$ for concrete taken from the floor was $34.9 \pm 1.50 \mathrm{~Bq} / \mathrm{kg}, 23.6 \pm 1.1 \mathrm{~Bq} / \mathrm{kg}$, and $484 \pm 37 \mathrm{~Bq} / \mathrm{kg}$, respectively. On the other hand, the concentration of radium and potassium isotopes for four rock samples taken from the corridor was on average $27.4 \pm 1.1 \mathrm{~Bq} / \mathrm{kg} 15.3 \pm 0.9 \mathrm{~Bq} / \mathrm{kg}$ and $238 \pm 20$ $\mathrm{Bq} / \mathrm{kg}$ for ${ }^{226} \mathrm{Ra},{ }^{228} \mathrm{Ra}\left({ }^{232} \mathrm{Th}\right)$, and ${ }^{40} \mathrm{~K}$, respectively [4].

\subsubsection{Neutron activation of the rock sample}

The crushed rock sample (from the wall of Hall 2) was activated by neutron flux from a ${ }^{252} \mathrm{Cf}$ source for one month. Immediately after activation, the gamma-ray spectra were measured by gamma spectroscopy with a lead-shielded HPGe detector (detection relative efficiency 20\%). Measurements were carried out in several cycles.

The following isotopes were identified on the recorded gamma-ray spectra: ${ }^{46} \mathrm{Sc},{ }^{59} \mathrm{Fe},{ }^{56} \mathrm{Mn}$, ${ }^{28} \mathrm{Al},{ }^{60} \mathrm{Co},{ }^{24} \mathrm{Na}$, which were formed in the reaction $(\mathrm{n}, \gamma)$.

\section{Summary}

The standard scheme for Callio Lab presented in this work is still supplemented with measurements carried out in Lab 3 and Lab 4. A similar scheme has been developed for another underground laboratory participating in the EUL and BSUIN projects, i.e., the Reiche Zeche mine located in Germany, the Polkowice-Sieroszowice mine (Conceptual Lab development coordinated by KGHM Cuprum R\&D center, Poland), and Experimental Barbara mine (Poland). Some natural radioactivity measurements in the scheme for the Reiche Zeche mine are presented in [5] and [6].

\section{Acknowledgment}

This study was performed under the Baltic Sea Underground Innovation Network (BSUIN) and Empowering Underground Laboratories Network Usage (EUL) projects supported by the EU's Interreg Baltic Sea Region Programme and the Research Excellence Initiative of the University of Silesia in Katowice.

\section{References}

[1] Baltic Sea Underground Innovation Network (BSUIN), https://bsuin.eu

[2] European Underground Laboratories Network Usage (EUL), https://undergroundlabs.network

[3] CALLIO LAB, Underground Center for Science and R\&D, https://calliolab.com/

[4] K. Polaczek-Grelik et al., Natural background radiation at Lab 2 of Callio Lab, Pyhäsalmi mine in Finland, Nucl. Instrum. Meth. A, 969 (2020) 164015.

[5] K. Polaczek-Grelik et al., Characterization of the radiation environment at TU Bergakademie in Freiberg, Saxony, Germany, Nucl. Instrum. Meth. A, 946 (2019) 162652.

[6] K. Szkliniarz et al., Characteristics of Natural Radioactivity at the Reiche Zeche Mine, Germany, Acta Phys. Pol. B Proc. Suppl., 13 (2020) 753. 